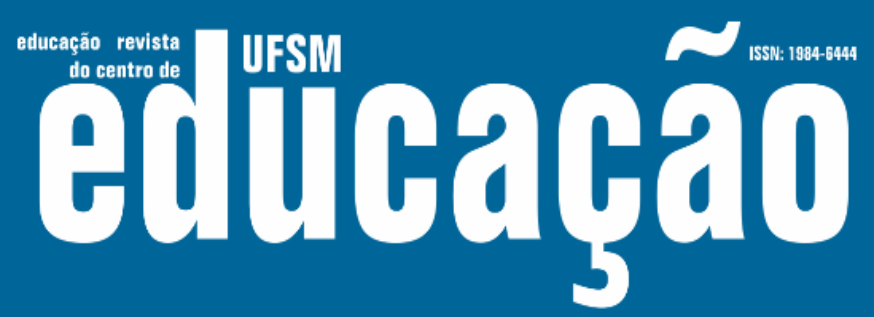

ISSN: 1984-6444 | http://dx.doi.org/10.5902/1984644431798

\title{
A criança e o seu mundo: considerações acerca da educação natural nos dois primeiros livros do Emílio de Rousseau
}

The child and its world: considerations about natural education in the two first books of Rousseau Emile

Fernando Dala Santa

Doutor em Educação pelo PPGEdu da Universidade de Passo Fundo. Pssso Fundo, Rio Grande do Sul, Brasil.

fernandos.101@hotmail.com - https://orcid.org/0000-0003-2156-5409

Recebido em 23 de março de 2018

Aprovado em 24 de maio de 2018

Publicado em 31 de janeiro de 2020

\section{RESUMO}

No presente artigo objetivamos abordar alguns aspectos da educação natural pensada para a infância, expostos nos Livros I e II da obra Emílio ou da Educação, de Jean-Jacques Rousseau. O conceito de educação natural permite perceber a vinculação de Rousseau ao movimento iluminista, ao mesmo tempo em que revela o modo como argumenta enquanto crítico da razão. Na primeira infância a educação natural estaria fortemente ligada à tensão entre as necessidades infantis e a intervenção adulta, cujo equilíbrio iria permitir que a criança pudesse se desenvolver em consonância com a natureza. A segunda infância, por seu turno, seria permeada por uma educação de cunho sensível, em meio a jogos e brincadeiras, favorecendo a robustez física e o refinamento dos sentidos. A educação natural estaria fundamentada, nessa perspectiva, no respeito ao mundo infantil e na consequente compreensão da criança como ser completo em sua condição especial de desenvolvimento, o que a insere em um plano pedagógico cujo mote seria a formação do homem em sentido amplo.

Palavras-chave: Educação natural; Infância; Mundo da criança.

\section{ABSTRACT}

The article deals with the some aspects of natural education for childhood, as described in Books I and II of the Emile or On Education work by Jean-Jacques Rousseau. The concept of natural education allows us to perceive Rousseau's connection to the Enlightenment movement, while revealing how he argues as a critic of reason. In the childhood the natural education should be related to the tension between the children needs and adult intervention, their balance would allow the child 


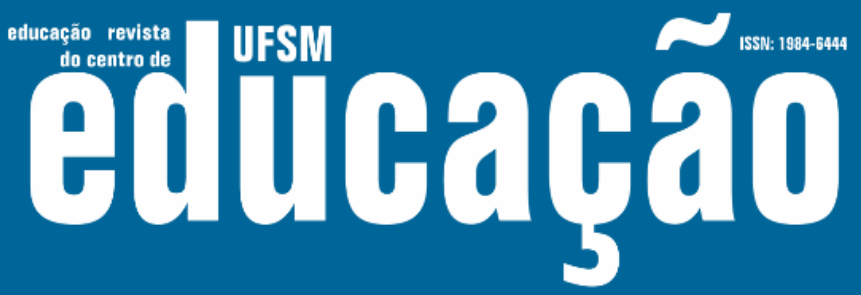

ISSN: 1984-6444 | http://dx.doi.org/10.5902/1984644431798

to develop in harmony with nature. The second childhood, in turn, would be permeated by an education in the midst of games and games, favoring a physical robustness and refinement of the senses. Natural education is based, in this perspective, on respect for the world of children and consequent understanding of the child as being complete in his special condition of development, which inserts it in a pedagogical plan whose objective would be the formation of the man in a broad sense.

Keywords: Natural education; Childhood; Child's world.

\section{Introdução}

Em que pese à distância temporal que nos separa do século XVIII e da gênese do movimento iluminista, o diálogo crítico com os seus pressupostos filosóficopedagógicos ainda é capaz de fomentar profícuos questionamentos acerca dos rumos que a nossa sociedade pode tomar no tocante aos aspectos sócio-políticos e educacionais. Ressaltamos, porém, que o apelo à tradição intelectual passada não se efetiva em vista de respostas para problemas específicos, já que pretende estabelecer uma reflexão acerca da contemporaneidade à luz do manancial de conceitos legados pelos pensadores que nos precederam.

O pensamento de Jean-Jacques Rousseau, pela sua profusão e inegável atualidade, se coloca como leitura obrigatória no processo formativo dos profissionais em educação, especialmente a sua grande obra pedagógica Emílio ou da Educação ${ }^{1}$ (1995). Todavia o estilo paradoxal da argumentação rousseauniana tem gerado historicamente inúmeras controvérsias, pautadas em interpretações parciais de um pensamento que só pode ser compreendido a partir de uma leitura abrangente. Portanto, o retorno à natureza significa para Rousseau o resgate daquilo que se perdeu com o processo civilizatório que acabou por tomar a razão como simples instrumento. Isso significa que voltar a ouvir a voz da natureza, que em última análise é ouvir a própria consciência, seria a condição basilar de um modelo formativo que visasse fazer frente à corrupção imperante na sociedade.

No presente artigo, pretendemos resgatar alguns dos pressupostos da educação natural de Rousseau pensada para a infância nos Livros I e II do Emílio, tendo como fio condutor a ideia de respeito ao mundo da criança. Para tanto, buscamos nos ater mais à essência do modelo educacional que o filósofo pretende 


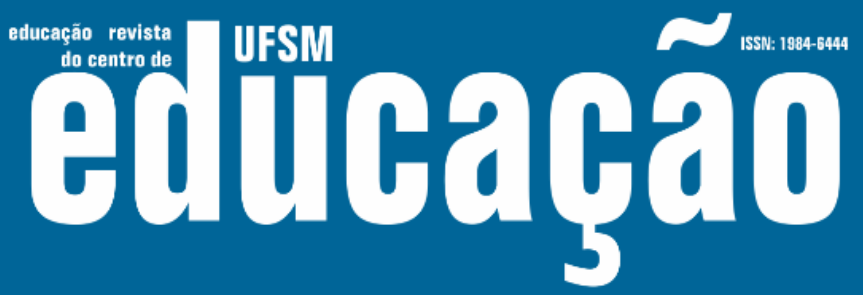

ISSN: 1984-6444 | http://dx.doi.org/10.5902/1984644431798

demonstrar do que às minúcias da ficção em que ele se encontra inserido. Fazemos tal advertência devido ao caráter do texto do Emílio, que configura não um tratado pedagógico, mas um romance de formação (a exemplo da obra de Goethe Os Anos de aprendizado de Wilhelm Meister [1994]), cuja leitura, quando voltada para um viés acadêmico, não pode prender-se à literalidade da narrativa e sim buscar a compreensão do que a narrativa pressupõe, tendo sempre em mente o contexto sóciohistórico a que ela se vincula. Tal postura hermenêutica é muito próxima à exigida pela leitura dos diálogos platônicos, por exemplo, que inviabilizam uma abordagem linear, na medida em que o jogo dialético que os constitui não é facilmente apreensível.

Com efeito, empreendemos uma breve caracterização do lluminismo, destacando o modo peculiar com que Rousseau se enquadra nesse movimento e a crítica que realiza à corrupção humana, surgida de maneira correlata ao progresso técnico-científico. Examinamos também os traços fundamentais da ideia de uma educação natural descrita no Emílio, pensada em conexão com os aspectos éticopolíticos do pensamento de Rousseau em sua configuração mais abrangente. Posteriormente, abordamos a educação natural no Livro I do Emílio a partir da tensão entre as carências infantis e a intervenção adulta e no Livro II com base no panorama de uma educação sensível para a segunda infância, que objetivaria o refinamento dos sentidos e o fortalecimento do corpo. Assim, consideramos poder dar conta da consecução dos objetivos que o presente estudo se coloca, apresentando, em linhas gerais, as diretrizes da proposta rousseauniana de educação natural, com ênfase na observação da criança em sua condição peculiar e no respeito a tudo que concerne ao horizonte próprio da educação infantil.

\section{O pensamento de Rousseau no âmbito do lluminismo}

O lluminismo foi um movimento intelectual que teve sua origem na França no decorrer do século XVIII, também chamado de "século das luzes", enquanto manifestação ampla de pensamento - filosófico, pedagógico e político -, irradiandose, posteriormente, por toda a Europa ${ }^{2}$ ao alcançar as camadas cultas da sociedade 


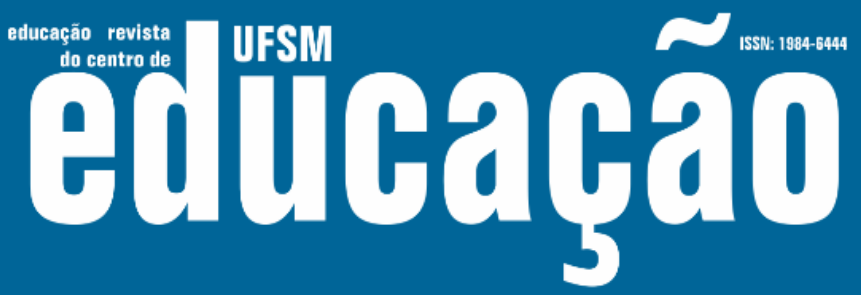

ISSN: 1984-6444 | http://dx.doi.org/10.5902/1984644431798

e ainda elementos da ascendente classe burguesa. Não obstante à profusão de interesses de seus representantes, o lluminismo era fundamentalmente marcado "pela crítica ao regime feudal, ao poder exercido pela nobreza e pelo clero, e pela crença no potencial emancipador da razão humana, canalizada na época, pelo desenvolvimento de novas teorias e experimentos" (DALBOSCO, 2011, p. 114). Para Reale e Antiseri, as similitudes que tornam possível nos reportarmos a um "iluminismo em geral", mesmo frente aos traços idiossincráticos referentes a cada manifestação particular, podem ser caracterizadas na forma de um modelo racional que se explicitava

\begin{abstract}
como defesa do conhecimento científico e da técnica enquanto instrumentos de transformação do mundo e de melhoria progressiva das condições espirituais e materiais da humanidade; como tolerância ética e religiosa; como defesa dos inalienáveis direitos naturais do homem e do cidadão; como rejeição dos dogmáticos sistemas metafísicos factualmente incontroláveis; como crítica daquelas superstições que seriam constituídas pelas religiões positivas e como defesa do deísmo (mas também do materialismo); como luta contra os privilégios e a tirania (REALE; ANTISERI, 1999, p. 670).
\end{abstract}

No contexto iluminista, somente a livre realização das capacidades humanas poderia fomentar a evolução científica, cujo mote era o progresso e a felicidade para o gênero humano. Daí a importância central da ideia de autonomia e a configuração de um conceito de razão distinto daqueles sustentados pelos sistemas metafísicos que se mantiveram hegemônicos desde o mundo grego. Se até o século XVII a razão era compreendida como a esfera das verdades eternas, comuns ao espírito humano e ao divino, o século XVIII irá Ihe conceder um sentido mais modesto: "deixou de ser a soma de 'ideias inatas', anteriores a toda a experiência, que nos revela a essência absoluta das coisas. A razão define-se muito menos como uma possessão do que como uma forma de aquisição" (CASSIRER, 1992, p. 32). De revelação divina ou adequação à verdade emanada da tradição, a razão passa a ser encarada enquanto disposição de espírito que se efetivaria em um duplo movimento, que desconstrói a nefasta influência de toda "verdade pré-fabricada", e posteriormente permite a edificação de uma totalidade estruturada segundo as regras ditadas pela própria razão, "não como a ideia de um ser, mas como a de um fazer" (CASSIRER, 1992, p. 33). 


\section{F HWM

ISSN: 1984-6444 | http://dx.doi.org/10.5902/1984644431798

No texto Resposta à pergunta: o que é esclarecimento? ${ }^{3}$ (publicado originalmente em 1783), Kant afirma de modo paradigmático que "esclarecimento é a saída do ser humano de sua menoridade, essa na qual ele se inseriu por sua própria culpa. Menoridade é a incapacidade de se servir de seu próprio entendimento sem a condução de outrem" (KANT, 2011, p. 23). A superação da menoridade caracteriza a saída de um estado de dependência na qual a falta de "resolução e coragem" de usar autonomamente a própria razão aprisiona grande parte dos homens. A luta contra a ignorância e o obscurantismo, bem como a busca pela autonomia mediante o uso pleno da razão e o questionamento crítico dos conteúdos legados pela tradição, tornaram-se as principais bandeiras do iluminismo. "Sapere aude! Tenha coragem de te servir de teu próprio entendimento! - este é, portanto, o lema do Esclarecimento" (KANT, 2011, p. 24).

Embora o "Século das Luzes" tenha forjado seus ideais amplamente fundamentado em uma crença na razão enquanto mola propulsora para o desenvolvimento humano, fosse ele técnico, moral ou intelectual, o otimismo inerente à confiança iluminista no potencial emancipador da razão e da ciência não expressava uma convicção unânime. Especialmente no que se refere à sua vertente francesa, o lluminismo nunca se caracterizou como um movimento unitário, manifestando-se por meio de diferentes "posições filosóficas, as quais estão permeadas por uma tensão crucial entre, por um lado, esperanças de novidades extraordinárias, a serem geradas pelo poder da razão e da ciência e, por outro, angústias de catástrofes naturais e sociais iminentes" (DALBOSCO, 2011, p. 115).

Sem dúvida, tal postura de ambígua vinculação é a que melhor simboliza a perspectiva intelectual adotada por Jean-Jacques Rousseau, nos termos em que, embora compartilhe de parte considerável do ideário iluminista, interpreta negativamente o progresso artístico e técnico-científico em sua influência sobre as instituições sociais. Para Cassirer (1992, p. 356-357) Rousseau "descobre que é problemática e inteiramente contestável a unidade que se admitia até então, ingenuamente e de boa-fé, existir entre consciência moral e consciência cultural em geral". A crítica de Rousseau se refere ao fato de que o avanço técnico-científico, ao 


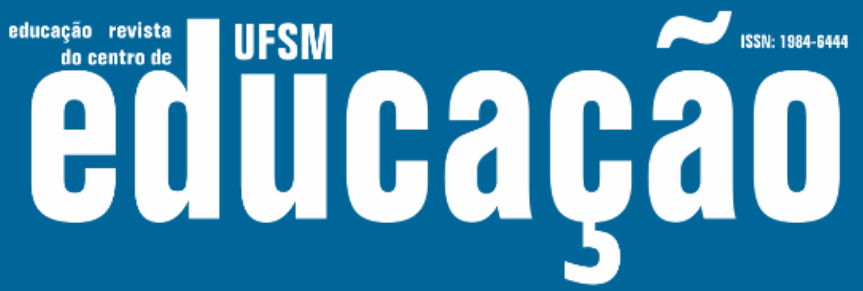

ISSN: 1984-6444 | http://dx.doi.org/10.5902/1984644431798

invés de proporcionar liberdade e felicidade estaria corrompendo o homem, afastando-o da natureza.

Rousseau ampara a constituição de seu pensamento político-educacional em uma hipótese e em uma constatação. A hipótese se refere à noção de um estado de natureza pré-político e pré-social, no qual o homem seria essencialmente bom, vivendo em contato direto com as coisas, sem estabelecer relações com outros indivíduos. Já a constatação alude à degeneração observável em sua época, que enredava o homem em uma teia de convencionalismo e artificialidade, um mundo de aparências (HOTTOIS, 1999, p. 134). O que leva a bondade do homem primitivo, guiado pelo amor de si, a transmutar-se na decadência do homem civilizado que se centra no egoísmo do amor próprio, são, em última instância, as más instituições, sustentadas por uma educação equivocada. No entanto, Rousseau não pretende um retrocesso ao estado primitivo, posto que ele é apenas um elemento ficcional cuja função seria fornecer o contraponto teórico à corrupção presente na sociedade. Objetiva o resgate daquilo que o homem havia perdido ao se desviar da natureza e que o permitiria viver em comunidade de modo harmônico.

Por outro lado, Rousseau concebe o homem como um ser ambivalente, dado que as características que o tornam verdadeiramente humano não lhes são inerentes, mas construídas no contato com determinada cultura e sociedade. Por essa razão a perfectibilidade humana, ou seja, a disposição intrínseca à condição humana que permite ao indivíduo converter-se em algo diferente do que é, pode levá-lo a tornar-se culto, mas engendra, na mesma medida, tensões e conflitos que seriam as raízes do mal. Em outros termos, a possibilidade de efetivação das potencialidades humanas tem a mesma origem que o seu mau uso (BÖHM, 2010, p. 81-82).

Se Rousseau não era um ingênuo adepto da crença otimista no poder libertador da razão, tampouco pode ser considerado um primitivista que postula o retorno do homem ao seu estado natural, prefigurado na imagem do "bom selvagem". O aspecto paradoxal do pensamento rousseauniano, que parece autorizar leituras tão distintas (otimismo ingênuo ou primitivismo conservador), na verdade conflui para uma solução conciliatória se o interpretarmos nos termos de uma dialética da razão, expressa na "compreensão adequada da tensão imanente à ação humana que se manifesta entre 


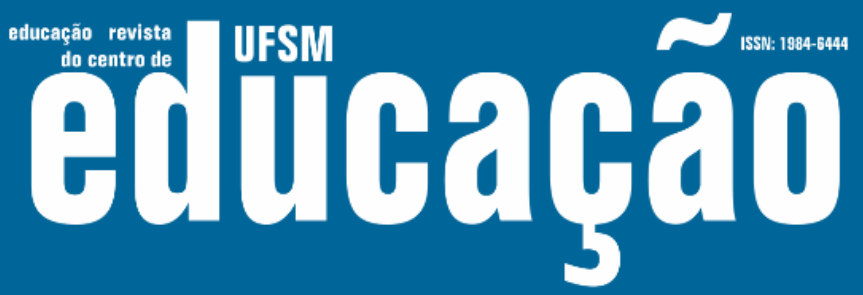

ISSN: 1984-6444 | http://dx.doi.org/10.5902/1984644431798

as dimensões da consciência (enquanto instinto humano e 'divino') e da razão, ambas inseridas em uma ordem universal" (DALBOSCO, 2011, p. 115). A dialética da razão tende a ampliar o modo de percepção das ações humanas, entendendo que os sentimentos são princípios constitutivos do agir racional, o que indica um protótipo de razão que não se limita aos seus aspectos lógico-formais, justamente por possuir também uma vinculação sensível.

\section{O projeto rousseauniano de uma educação natural}

No que se refere especificamente à questão pedagógica, Rousseau expressa no Emílio a idealização de um modelo formativo-educacional de um aluno fictício (Emílio), do seu nascimento até a entrada na vida adulta. Com efeito, no Emílio Rousseau não se propõe a deslindar as noções fundamentais da ação pedagógica enquanto manual prático de educação infantil, pretendia, ao contrário, fazer da educação um projeto de formação humana: "saindo de minhas mãos, ele [Emílio] não será, concordo, nem magistrado, nem soldado, nem padre; será primeiramente um homem. Tudo o que um homem deve ser, ele o saberá, se necessário, tão bem quanto quem quer que seja" (ROUSSEAU, 1995, p. 15). Gómez (2016, p. 198) reitera que esse processo educativo é, em grande medida, um regime autoformativo que se refere à potencialização do "discípulo" e não à sua submissão. A formação humana em um sentido amplo era única via para vencer a corrupção social que cada vez mais forçava o homem a transmutar-se em escravo, mesmo no âmago de uma sociedade que alardeava ter entre suas premissas centrais a possibilidade de que os indivíduos desfrutassem da liberdade e do progresso, pois "aquele que se crê senhor dos outros, não deixa de ser mais escravo que eles" (ROUSSEAU, 1996, p. 09). Ademais, o luxo e a opulência, signos de prosperidade e distinção social, são responsáveis por inviabilizar a moral pública (DELGADO, 2016, p. 49)

Para Rousseau não se mostrava possível tratar verdadeiramente da questão política sem a postulação de uma teoria educacional. "A política implica antes de tudo a educação do cidadão. Apenas homens esclarecidos não se deixarão enganar por insidiosas propagandas, terão como única paixão o amor pela pátria, só eles poderão 


\section{Fusm Eulloahá}

ISSN: 1984-6444 | http://dx.doi.org/10.5902/1984644431798

estabelecer uma sociedade justa" (BURGELIN, 1996, p. XXII). Os arquétipos de estado e de educação rousseaunianos formam uma indissociável unidade relacional, de maneira que a pedagogia integra o panorama de uma antropologia filosófica e de uma teoria da sociedade que se conjugam no projeto de formação voltado para o autogoverno: a educação é o processo seguro para criar as condições de existência de uma vida humana livre (GÓMEZ, 2016, p. 203). Os princípios de uma educação natural se revestem, pois, de um caráter eminentemente político, na medida em que "a participação soberana do cidadão adulto no modelo republicano governado pela vontade geral pressupõe um longo processo formativo do homem que deve iniciar já na sua primeira infância" (DALBOSCO, 2007, p. 313).

O Emílio não pode ser lido de modo dissociado das demais obras de Rousseau, sobretudo no que se refere ao segundo Discurso ${ }^{4}$ (1991) e ao Contrato Social (1996). Isso significa que o Emílio não carrega apenas reflexões periféricas, mas constitui parte fundamental de um todo coerente. A concepção de que o pensamento de Rousseau pode ser entendido mediante a um marco teórico mais amplo indica a síntese educacional possível entre a perda da liberdade natural - que leva ao crescente artificialismo e condicionalismo das relações sociais - e a autenticidade subjetiva entendida a partir da liberdade jurídico-moral. A possibilidade de um estado justo estaria subordinada à educação virtuosa da vontade, "portanto, sem descaracterizar a liberdade natural, Emílio vê na liberdade moral a forma de assegurar a autenticidade da ação humana" (DALBOSCO, 2011, p. 129). A esse respeito, Starobinski (1991, p. 42-43) destaca que Kant e Cassirer, ao se pautarem no Emílio e nas teorias pedagógicas de Rousseau, diferentemente da interpretação de Hegel que previa uma síntese pela revolução, consideram a educação como o elo que une as análises do segundo Discurso à construção positiva do Contrato Social.

Por conseguinte, a proposta de Rousseau de regresso à natureza significaria 0 salutar retorno à interioridade humana. Se a sociedade era capaz de corromper o indivíduo, seria imperioso opor à racionalidade iluminista, toda exteriorizada, "uma racionalidade interiorizada, em condições de recuperar a voz da consciência" (REALE; ANTISERI, 1999, p. 767). A educação deveria efetivar-se afastada da influência corruptora da sociedade, mantendo-se ligada às exigências próprias da natureza. No 


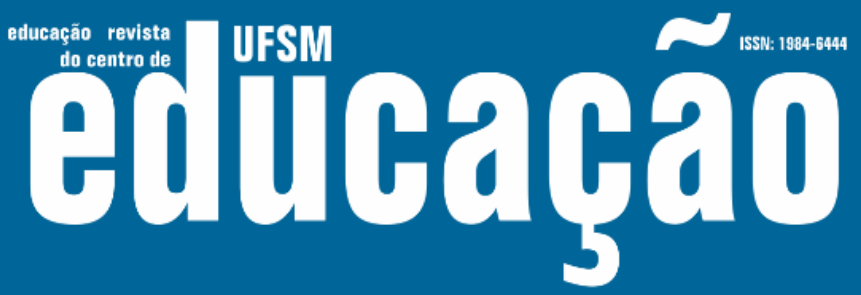

ISSN: 1984-6444 | http://dx.doi.org/10.5902/1984644431798

entanto, Soëtard (2010, p. 67) destaca que o conceito de "natureza" pode assumir em Rousseau três distintas significações: a) oposição ao que é social; b) valorização das necessidades espontâneas da criança e dos processos livres de desenvolvimento; c) exigência de um convívio com ambientes não urbanos, considerados genuínos.

Em suma, a educação natural poderia ser entendida como o processo formativo que permite ao homem ser aquilo que efetivamente ele é, que desenvolve suas capacidades intrínsecas e o torna apto para agir com autonomia nos termos da liberdade moral, que, em si mesma, não se contrapõe à liberdade natural. "Esta coincidência entre liberdade e lei representa o estágio mais elevado de humanidade, que outra coisa não é senão a própria vontade moral" (DALBOSCO, 2016, p. 17). Enfaticamente, poderíamos afirmar que a educação natural menos impõe um arquétipo de homem a ser buscado do que orienta a livre progressão do potencial humano inerente a cada indivíduo.

Não há dúvida de que as concepções do Emílio engendram uma verdadeira revolução pedagógica ao estabelecerem uma abordagem centrada na criança, tendo em vista as limitações e potencialidades que lhe são próprias, contrariamente à prática tradicional que privilegiava a transmissão vertical de conhecimentos prédeterminados. Destarte, é como crítico da razão que Rousseau se coloca em condições de "avaliar o modo como as crianças eram tratadas em sua época e, ao mesmo tempo, justificar a importância pedagógica de serem respeitadas como crianças, isto é, em seu próprio mundo" (DALBOSCO, 2011, p. 113). Entretanto, seria um reducionismo leviano interpretar o deslocamento do foco do processo pedagógico para a criança apartado dos aspectos sociais, ou julgar que ele levaria a uma permissividade pedagógica no que concerne aos desejos infantis. Afirma Soëtard (2010, p. 12) que Rousseau "reagiu também contra a complacência desmedida do adulto em relação ao que tendia a se tornar o centro do mundo: se, por um lado, é necessário rejeitar a imagem da criança, fruto do pecado, por outro, não se pode divinizar seus desejos". A atenção pedagógica aos elementos constitutivos do mundo infantil não desresponsabiliza o adulto de sua decisiva incumbência de propiciar e garantir as condições para que a educação natural se efetive plenamente. 


\section{T usm Eulloabुa}

ISSN: 1984-6444 | http://dx.doi.org/10.5902/1984644431798

Rousseau aponta o erro até então cometido na prática de ensino que se detém apenas às necessidades adultas, a despeito do que as crianças estavam em condições de aprender: "procuram sempre o homem na criança, sem pensar no que esta é, antes de ser homem" (ROUSSEAU, 1995, p. 06). Tal modelo educacional teria como resultado invariavelmente a corrupção das crianças, já que projetaria sobre a infância interesses e predileções próprias do universo adulto, sem atenção a tudo que constitui o horizonte de desenvolvimento infantil. Com efeito, Rousseau postula a premência de que a criança fosse compreendida enquanto um ser completo em sua condição especial, ao invés de apenas um adulto em miniatura.

O projeto rousseauniano de uma educação natural, pela sua vinculação iluminista, está umbilicalmente ligado ao tema da razão, embora ampliado de modo a compreender também a dimensão sensível do ser humano.

Rousseau continua sendo um produto genuíno do Século das Luzes, mas seu racionalismo coabita abertamente, nele, com seu adversário de sempre - aquele contra o qual Platão e Descartes erigiram seus sistemas de pensamento: o eu sensível, que afirma sua própria verdade na autenticidade de uma existência coerente consigo mesma. Assim, para Rousseau, a educação será a arte de gerir os contrários, na perspectiva do desenvolvimento da liberdade autônoma (SOËTARD, 2010, p. 16).

Para Rousseau o ponto de partida do conhecimento não é a teoria, mas a experiência, o que por si só revela uma inequívoca crítica ao intelectualismo verbalizado presente na educação da sua época. E ao incorporar a ideia de que o conhecimento se origina nos sentidos, sendo nesse aspecto tributário de John Locke, Rousseau se afasta definitivamente da metafísica racionalista especulativa. Tal guinada em direção ao empirismo requeria o abandono de um método dedutivo de educação e a adoção de uma observação acurada acerca do modo como as crianças vivem e se desenvolvem social, intelectual e afetivamente. O mundo infantil em seu estado inicial é sensitivo e não racional, exigindo que a educação das crianças possua um caráter sensível com objetivo de fortalecer o julgamento crítico, para que quando adultos sejam capazes de pensar por si mesmos. Passamos na sequência a analisar o que Rousseau compreende por primeira infância e o modo como concebe a função educativa do adulto. 


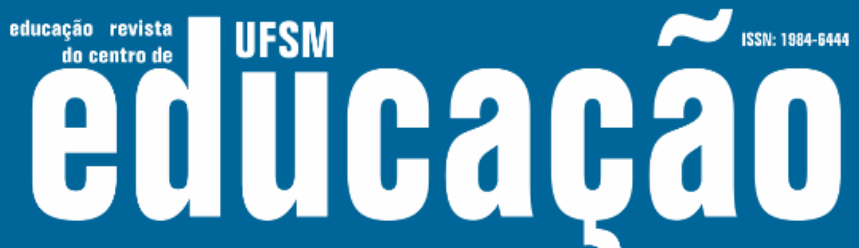

ISSN: 1984-6444 | http://dx.doi.org/10.5902/1984644431798

\section{Educação natural na primeira infância: a tensão entre as necessidades infantis e a intervenção adulta}

Rousseau estabelece a primeira infância como o período compreendido entre o nascimento e os 2 anos de idade. Nesta fase do desenvolvimento infantil a educação possui uma importância fundamental, centrando-se na questão acerca das necessidades da criança e dos cuidados do adulto. Fica claro que a educação natural inicia com o nascimento do indivíduo, tanto que mesmo "antes de falar, antes de compreender, já ele se instruí. A experiência adianta-se às lições" (ROUSSEAU, 1995, p. 42). Afirma Dalbosco (2007, p. 314) que "o projeto de uma educação natural, quando voltada à infância, visa à formação de uma criança 'capaz de ser rainha de si mesma' e, por meio do confronto permanente com diferentes tipos de provações, disciplinar progressivamente seus desejos". Esse ideal de educação depende de como é pensada a ação do adulto em relação à criança, no tocante à tensão entre autoritarismo e espontaneísmo, manifesta na viva possibilidade "de ensinar às crianças o que aprenderiam muito melhor sozinhas e esquecer o que somente nós Ihes poderíamos ensinar" (ROUSSEAU, 1995, p. 59).

É essencial que exista um equilíbrio entre a garantia de respeito ao mundo da criança frente a uma possível colonização adulta e o total isolamento infantil do convívio social. Sem dúvida, esta é uma das funções centrais da educação natural, "pensar e preparar o ingresso progressivo da criança na sociedade, evitando que tal ingresso signifique, ao mesmo tempo, a desfiguração do mundo infantil" (DALBOSCO, 2009, p. 177). Nesses termos, o Livro I do Emílio evidencia que a interferência adulta deve se resumir ao fornecimento dos cuidados indispensáveis ao desenvolvimento natural da criança, que embora seja na primeira infância um ser ainda muito dependente, precisa enfrentar as provações impostas pela natureza de maneira a forjar o seu corpo e o seu caráter. "Observai a natureza e segui o caminho que ela vos indica. Ela exercita continuamente as crianças; ela enrijece seu temperamento mediante experiências de toda espécie; ela ensina-Ihes desde cedo o que é pena e dor" (ROUSSEAU, 1995, p. 22). 


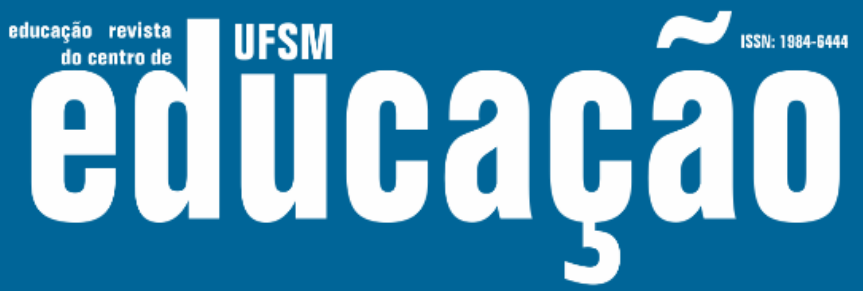

ISSN: 1984-6444 | http://dx.doi.org/10.5902/1984644431798

O princípio pedagógico da educação pelas coisas é o caminho que indica ao adulto a maneira equilibrada de empreender sua intervenção educativa. A educação pelas coisas assinala a forma de experienciar os objetos que afetam os sentidos, pensada tendo em vista o contexto das limitações e potencialidades infantis. Em substituição aos traços pedagógicos de cunho verbalista e impositivo, a educação pelas coisas se ampara mais no exemplo e nas afecções que a experiência sensitiva proporciona. Uma leitura apressada poderia levar ao questionamento se o simples apelo ao princípio da educação pelas coisas não se revelaria uma estratégia pedagógica insuficiente na tarefa de abarcar também questões de ordem moral. Todavia, está claro para Rousseau que a educação natural em sua configuração voltada para a primeira infância não objetiva introduzir a criança diretamente nos princípios da moralidade, mas atentar para a "formação saudável de seu corpo e o desenvolvimento de sua sensibilidade por meio da educação pelas coisas" (DALBOSCO, 2009, p. 182).

No âmbito da primeira infância, tampouco é possível estabelecer o trato pedagógico privilegiando a negociação argumentativa entre adulto e criança, na medida em que esta ainda não possui uma linguagem articulada, e encara o mundo a sua volta pautada em sentimentos "de império ou de servidão" (ROUSSEAU, 1995, p. 24). Isso significa que a ação imprópria do adulto em seus cuidados pode tornar a criança, ao mesmo tempo, escrava e tirana. Nessa fase, a criança não possui a capacidade de compreender e compor um discurso racional, bem como carece de referenciais de ordem moral que as fizesse autônoma em suas decisões. Logo, "a educação argumentativa não tem o mesmo poder de esclarecimento e convencimento como tem os exemplos extraídos da simples funcionalidade das coisas, com seus respectivos riscos, possibilidades e proibições" (DALBOSCO, 2009, p. 180). Torna-se evidente mais uma vez a tensão entre a possibilidade de imposição vertical da vontade adulta de um lado, e de outro a igualmente prejudicial submissão aos caprichos da criança.

Por conseguinte, é imprescindível que o adulto esteja apto a discernir necessidades autênticas de necessidades fantasiosas e, nesse processo educativo, conduza criança ao passo que permita que ela se desenvolva por si mesma. Quando 


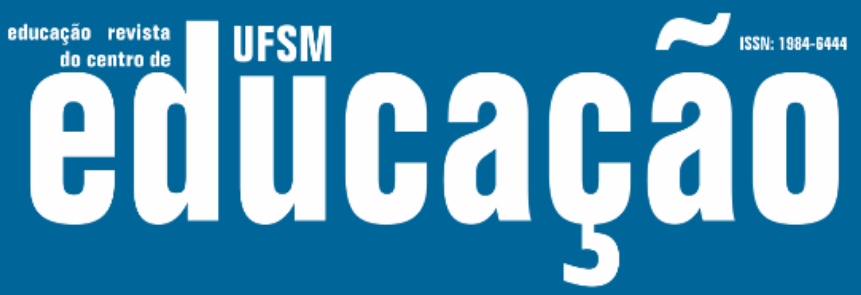

ISSN: 1984-6444 | http://dx.doi.org/10.5902/1984644431798

a criança se vê constrangida pelas suas limitações e carece de cuidados externos tende a comunicar a seu modo, isto é, mediante o choro, o mal-estar que lhe acomete (ROUSSEAU, 1995, p. 45). E sendo o choro a linguagem característica da primeira infância, deve ser tomado como critério para conhecer e interpretar as expressões pelas quais a criança estabelece contato com o mundo. "Desses choros que imaginamos tão pouco dignos de atenção, nasce a primeira relação do homem com tudo o que o cerca: forja-se o primeiro elo dessa grande cadeia de que é formada a ordem social" (ROUSSEAU, 1995, p. 46). Na forma como o adulto compreende o choro infantil repousa a chave para a sua ponderada intervenção, capaz de garantir o desenvolvimento natural da criança.

Todavia, por não estarem limitadas ao âmbito físico-biológico, identificar quais são as carências reais das crianças mostra-se na maioria das vezes uma tarefa complicada. Tal situação cria ingentes dificuldades, pois quando sucumbe inadvertidamente à vontade tirânica da criança, satisfazendo-lhe caprichos e não apenas necessidades, o adulto torna-se incapaz de orientá-la pelo caminho da natureza. Para que a ação pedagógica se reestabeleça na senda da educação natural, Rousseau (1995, p. 49-50) se empenha na formulação de quatro máximas: 1) por suas limitações, a criança não possui capacidade suficiente para satisfazer as exigências da natureza, cabendo ao adulto auxiliar para que ela utilize as forças de que dispõe naturalmente e das quais não pode abusar; 2) ajudar a criança a suprir suas carências no tocante à inteligência, força ou quaisquer necessidades de ordem física; 3) buscar atender unicamente ao útil real, sem curvar-se à fantasia e ao desejo sem razão; 4) atentar para a linguagem infantil, de modo a distinguir os desejos que vem da natureza daqueles oriundos da opinião.

O objetivo de tais máximas está em oferecer às crianças mais liberdade genuína e "menos voluntariedade, em deixá-las com que façam mais por si mesmas e exijam menos dos outros. Assim, acostumando-se desde cedo, a subordinar seus desejos à suas forças elas sentirão pouco a privação do que não estiver em seu poder" (ROUSSEAU, 1995, p. 50). A marcha da natureza pressupõe que os cuidados do adulto não se sobreponham ao progresso natural da criança em seu tempo próprio de maturação. $O$ respeito à criança em seu mundo significa permitir o desenvolvimento 


\section{Autนaดูลิ}

ISSN: 1984-6444 | http://dx.doi.org/10.5902/1984644431798

infantil mediante a satisfação das suas necessidades reais e do cuidado efetivo para que os caprichos não se tornem hábitos.

Contudo, no decorrer da primeira infância a criança constrói uma linguagem que possui gramática própria, com uma sintaxe de regras mais gerais (ROUSSEAU, 1995, p. 53), e que gradativamente vai substituir o choro, já na transição para a segunda infância, iniciando uma nova etapa no processo de formação sócio-cognitivo. A partir do momento em que aprende a falar a criança manifesta uma maior independência frente à influência adulta, uma vez que já pode recorrer à verbalização para expressar suas dores e sensações. A gênese e a consolidação da linguagem verbal também exigem um crescimento espontâneo, distante de tentativas artificiais de maturação, na medida em que "cada qual avança mais ou menos segundo seu gênio, seu gosto, suas necessidades, seus talentos, seu zelo e as oportunidades que tem" (ROUSSEAU, 1995, p. 42).

A compreensão de que a criança não é um adulto deficitário, mas um ser perfeito em suas especificidades, torna compreensível a insistência de Rousseau em ressaltar que ao educador não é permitido acelerar o processo pedagógico além do que a criança estiver em condições de suportar. Tal perspectiva, no que alude ao surgimento da fala, denota claramente o resultado nefasto da tentativa de ensinar palavras ou estruturas linguísticas excessivamente complexas para o nível cognitivo infantil, podendo levar à situação de que a criança possua "mais palavras que ideias, e saiba dizer mais coisas do que pode pensar" (ROUSSEAU, 1995, p. 57). Aqui, novamente aparece a tensão constitutiva da relação entre a ação interventiva do adulto e a possibilidade de que a criança evolua de maneira natural dentro dos limites de suas próprias forças, que, em síntese, é o pano de fundo sob o qual Rousseau constrói toda a argumentação do Livro I e prepara o leitor para o exame da segunda infância e das considerações relativas a este estágio da educação infantil.

\section{A segunda infância: uma educação sensível}

O livro II do Emílio passa a dissertar sobre o período da segunda infância, circunscrito entre os 2 e os 12 anos de idade. A proposta de educação natural pensada 


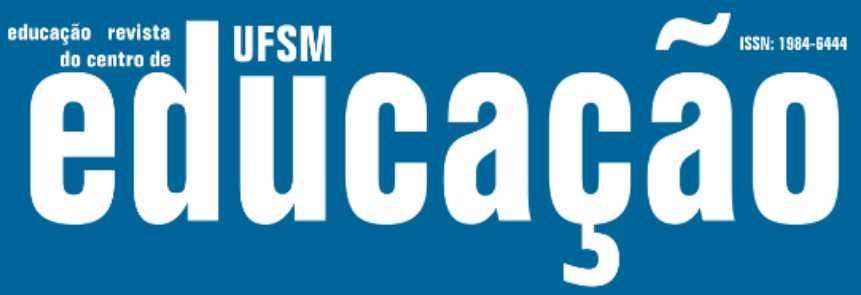

ISSN: 1984-6444 | http://dx.doi.org/10.5902/1984644431798

para a criança na fase da segunda infância segue o panorama do fortalecimento das suas capacidades físicas e sensoriais a partir do princípio da educação pelas coisas, cuja premissa pedagógica essencial ainda é o respeito ao mundo infantil. Isso conflui para a ideia de que na prática pedagógica tradicional, "a idade da alegria passa em meio aos choros, aos castigos, às ameaças, à escravidão" (ROUSSEAU, 1995, p. 60). Ao não ser considerada em sua condição especial de desenvolvimento, à criança eram negadas as condições para que vivesse de acordo com a ordem natural. Era imprescindível, pois, deixar a natureza agir por si mesma durante um longo período antes de tomar-lhe o lugar, a fim de não atuar de modo a contrariá-la em suas determinações (ROUSSEAU, 1995, p. 97).

A educação natural visaria preparar a criança para o convívio social sem deixála se contaminar pelos vícios presentes na sociedade, tendo, nesse sentido, uma função negativa, "ela consiste, não em ensinar a virtude ou a verdade, mas em preservar o coração do vício e o espírito do erro" (ROUSSEAU, 1995, p. 80). Caberia ao educador, antes de tudo, proteger a criança da invasão das pechas de um pensamento adulto, preparando-a para sua futura inserção autônoma no mundo social. Afirma Rousseau (1995, p. 92) que "quando não se tem pressa em instruir, não se tem pressa em exigir e aguarda-se o tempo necessário para só exigir oportunamente. Então a criança se forma na medida em que não se estraga". Desse modo, a influência da artificialidade e do convencionalismo presentes na sociedade precisa ser evitada a todo custo, para que a criança mantenha em consonância seus desejos e suas forças.

O contato direto com a natureza faz a criança aprender com a experiência das coisas. O exemplo mais elucidativo que Rousseau (1995, p. 88) apresenta acerca da educação pelas coisas é o do vidro quebrado da janela. Se a criança quebrar o vidro da janela de seu quarto, não deve o adulto admoesta-la e prontamente concertar a janela. Ao contrário, seria melhor que deixasse a criança experimentar as consequências de sua ação. Somente quando sentir o vento gelado invadir-lhe o quarto a criança compreenderá a gravidade de seu ato, e nesse momento o educador terá a possibilidade de fazer com que a lição seja corretamente aprendida. Tal exemplo evoca a importância de que o adulto possua sensibilidade pedagógica para 


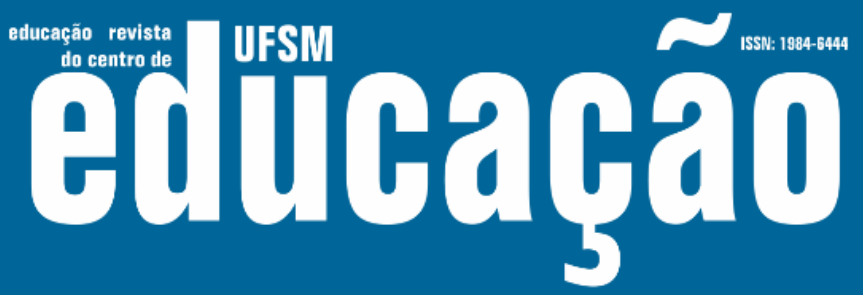

ISSN: 1984-6444 | http://dx.doi.org/10.5902/1984644431798

discernir em cada situação específica o modo de proceder em sua intervenção educativa. Para Dalbosco (2009, p. 180), "senso de observação, paciência, firmeza e serenidade parecem ser, neste caso, qualificativos do princípio da educação pelas coisas".

Por tal motivo, na educação pela experiência era necessário evitar os tediosos discursos moralizantes, que certamente soam vazios quando proferidos a indivíduos ainda não preparados para recebê-los criticamente. Rousseau é bastante claro quando desencoraja que se use com o aluno qualquer

espécie de lição verbal; só da experiência ele as deve receber; não Ihe inflijais nenhuma espécie de castigo, pois ele não sabe o que seja cometer uma falta; não the façais nunca pedir perdão, porquanto não pode ofender-vos. Desprovido de qualquer moralidade em suas ações, nada pode ele fazer que seja moralmente mal e que mereça castigo ou admoestação (ROUSSEAU, 1995, p. 78).

O ensino da virtude por meio da repetição de máximas verbalizadas poderia levar, na melhor das hipóteses, à imitação de ações virtuosas, totalmente destituídas de um valor moral consciente. Para Starobinski (1991, p. 213), não se pode impor à criança um esforço artificial que a distancie da realidade imediatamente percebida. Somente o aprendizado pela experiência fará da criança soberana no tocante aos seus próprios atos, na medida em que as virtudes por imitação são virtudes de símio e "nenhuma ação é moralmente boa senão quando feita nessa intenção e não porque outros a fazem" (ROUSSEAU, 1995, p. 94). Tal assertiva vai ao encontro da ideia de que na união oriunda do contrato social a força comum protege tudo o que concerne a seus membros em particular, embora cada um obedeça apenas "a si mesmo e permaneça tão livre quanto antes" (ROUSSEAU, 1996, p. 20). A autonomia necessária para a livre participação no estado republicano é, em grande medida, fruto de uma educação que fortaleça a disposições naturais da criança a partir das experiências sensíveis, mediadas por uma liberdade bem regrada, que "deve servir como ideal normativo regulador do princípio pedagógico de condução da criança ao caminho da natureza e, frente a isso, do modo como o adulto exerce seus cuidados" (DALBOSCO, 2009, p. 188). 


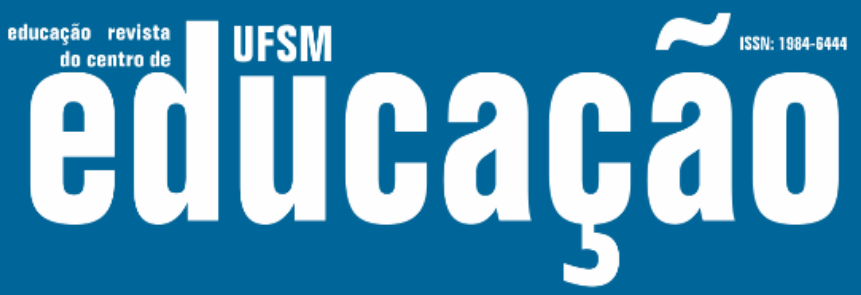

ISSN: 1984-6444 | http://dx.doi.org/10.5902/1984644431798

Como afirma Herb (2002, p. 76) "Rousseau é um moderno com alma antiga", não pode nos causar estranheza, portanto, o fato de que deixe transparecer em vários momentos a influência que Platão exerceu na constituição do seu pensamento político-educacional ${ }^{5}$, em especial no que concerne à ludicidade inerente à educação infantil. O tempo gasto com jogos e brincadeiras não é um tempo perdido, tanto que a criança muito aprende em sua aparente ociosidade, pois em nenhuma outra fase da vida verá seus dias tão repletos de ocupações. A esse respeito, Rousseau (1995, p. 97) destaca que "Platão, em sua República, que acreditam tão austera, só educa as crianças com festas, jogos, canções, passatempos: parece que fez tudo ensinandoIhes a se divertirem".

No tocante à necessidade de respeitar o mundo da criança, expressado aqui na preponderância do aspecto lúdico da educação infantil, Rousseau declaradamente se inspira na ideia platônica presente na República (536e-537a) de que nada permanece na alma que tenha entrado pela imposição: "não eduques as crianças no estudo pela violência, mas a brincar, a fim de ficares mais habilitado a descobrir tendências naturais de cada um". A condução diretiva da educação infantil, voltada para a instrução daquilo que será útil ao adulto, priva a criança de um aprendizado insubstituível e que diz respeito ao amadurecimento da sensibilidade e ao fortalecimento do corpo.

A segunda infância exige um modelo de educação sensível justamente por constituir um estágio em que impera o que Rousseau (1995, p. 164) chama de "razão pueril", conduzida pelo "país das sensações" por um método que não é outro senão o da natureza. Destarte, a educação natural, embora vislumbre como fim desejável no conjunto do seu programa pedagógico "um homem razoável", teria na segunda infância um enfoque eminentemente sensível. Rousseau (1995, p. 74) explica tal procedimento ao compreender que "de todas as capacidades do homem, a razão, que não é, por assim dizer, senão um composto de todas as outras, é a que se desenvolve mais dificilmente e mais tarde", tanto que "se a criança entendesse razão, não teria necessidade de ser educada". Nesse sentido, é desaconselhável que a criança em sua educação seja bombardeada por conteúdos, em maior quantidade e complexidade do que ela seria capaz de absorver. O excesso de conteúdos não é 


\section{Autนaดูลิ}

ISSN: 1984-6444 | http://dx.doi.org/10.5902/1984644431798

apenas inútil, mas também prejudicial à educação, já que poderia facilmente criar na criança uma perigosa aversão ao estudo. Rousseau (1995, p. 109-110) destaca com especial atenção a ideia de que a leitura, instrumento tão útil e tão agradável, pode transmutar-se em um grande suplício para as crianças quando imposta verticalmente tendo em vista objetivos sobre os quais elas não possuem interesse imediato, de onde se infere a necessidade de tornar a criança ávida por conhecer, fazendo coincidir sua curiosidade com aquilo que deve aprender.

A infância enquanto período da vida humana que detém um valor próprio, não pode ser encarada como se fosse apenas uma fase transitória marcada pela deficiência, pois "não é um lugar de passagem para outros estágios mais desenvolvidos" (STRECK, 2008, p. 35). A crítica de Rousseau recai sobre a ideia de que a criança seja uma miniatura imperfeita do homem adulto, sendo a infância um mal necessário no caminho do crescimento humano. Em suma, Rousseau (1995, p. 60) pretende evitar a "educação bárbara que sacrifica o presente a um futuro incerto", tornando a criança miserável entre castigos e provações em nome de uma felicidade que dificilmente the será acessível.

\section{Considerações finais}

Rousseau é um pensador cuja obra mantém uma assombrosa atualidade. Muitas das suas preocupações são semelhantes às que assolam o mundo contemporâneo e suas propostas nos forçam a refletir sobre o problema de como educar as crianças em meio à celeridade de um mundo em constante evolução técnica. O modo como articula os aspectos políticos e educacionais do seu pensamento aponta para a indelével comunhão entre uma educação adequada, que permitisse o florescimento de todas as capacidades humanas, e a autonomia necessária para a vida harmônica na sociedade republicana. Sua crítica recai especialmente sobre o distanciamento da ordem natural que encerra o homem em um protótipo de ordenamento social marcado pela artificialidade das relações.

No Emílio, o modelo de educação natural tem como uma de suas premissas fundamentais o respeito pela criança em seu próprio mundo. Tal assertiva nos impõe 


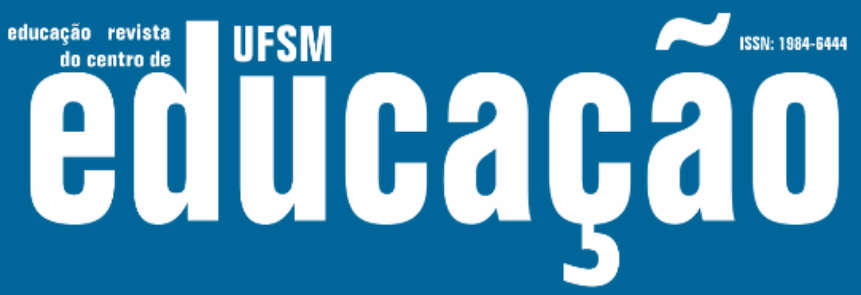

ISSN: 1984-6444 | http://dx.doi.org/10.5902/1984644431798

a urgência de que a criança seja considerada um ser perfeito em sua condição peculiar, com limitações e potencialidades que Ihes são próprias. Entretanto, na primeira infância a tensão constitutiva da relação entre as necessidades infantis e os cuidados adultos não é facilmente resolvida, restando sempre a possibilidade de que a educação peque pela falta ou excesso. Assim, seria preciso que o adulto soubesse identificar entre as exigências infantis quais tinham origem na natureza e quais eram fruto de meros caprichos. Por essa razão, Rousseau deixa transparecer que a intervenção adulta deve se restringir ao atendimento das necessidades reais da criança, permitindo que ela se desenvolva por si mesma, seguindo a marcha da natureza.

Nesse processo formativo, a educação pelas coisas surge como o princípio pedagógico que auxiliaria o adulto a empreender uma intervenção equilibrada, evitando escravizar a criança ou, por outro lado, tornar-se seu escravo. A educação pelas coisas se usa das afeç̧ões oriundas do contato direto com os objetos para estabelecer um aprendizado de ordem sensível, que resgataria a percepção acurada presente naqueles que vivem mais próximos da natureza. Já no âmbito da segunda infância a educação pela experiência das coisas expressa uma alternativa muito mais eficaz do que a prática educativa verbalizada, inócua na maioria das vezes. Permitir que a criança explore e conheça o mundo a sua volta lhe ensinará desde cedo a ser autônoma, a esperar mais de si mesma e menos dos outros.

$\mathrm{Na}$ infância ocorre para Rousseau o sono da razão, o que indica a premência de uma educação de cunho sensível, que garantisse o desenvolvimento de uma criança de compleição física robusta e sentidos apurados, avessa a qualquer tentativa prematura de imposição do ensino intelectualizado nos moldes tradicionais. O ensino puramente conteudista seria substituído pelo aprendizado de coisas úteis e em lugar das ciências o cultivo da curiosidade levaria as crianças espontaneamente ao encontro do conhecimento. A criança passaria a maior parte do seu tempo exercitando-se em jogos e brincadeiras, aprendendo aquilo que somente a natureza, sábia educadora, era capaz de ensinar.

Desse modo, na proteção do mundo infantil contra uma possível invasão adulta, a educação natural assumiria uma função negativa, tendo em vista não o ensino 


\section{Tilusm Eutthab̧a}

ISSN: 1984-6444 | http://dx.doi.org/10.5902/1984644431798

diretivo da virtude, mas fornecer à criança guarida contra um ambiente social viciado: seria, em suma, uma educação para a autenticidade. Ao forçar a criança a comportarse de acordo com as convenções adultas, o único resultado era a consolidação de virtudes simiescas, simples imitações de comportamentos desejáveis. Nesta constatação repousa a importância da liberdade bem regrada, que ao impor limites protege a criança do erro e do vício. O contato com a natureza permite à criança tornar-se senhora de si mesma, consciente de que seus desejos e suas capacidades nem sempre podem coincidir. Destarte, o princípio filosófico-pedagógico essencial presente no Emílio é a formação para o autogoverno: somente a educação virtuosa da vontade, a comunhão entre liberdade natural e liberdade moral, proporcionaria a autonomia necessária para o pleno exercício dos ideais republicanos.

\section{Referências}

BÖHM, Winfred. La história de la pedagogía: desde Platón hasta la actualidade. Villa Maria: Eduvim, 2010.

BURGELIN, Pierre. Prefácio. In. ROUSSEAU, Jean-Jacques. O contrato social. 3. ed. São Paulo: Martins Fontes, 1996, IX-XXIII.

CASSIRER, Ernest. A filosofia do iluminismo. Trad. Álvaro Cabral. Campinas: editora da Unicamp, 1992.

DALBOSCO, Claudio Almir. Primeira infância e educação natural em Rousseau: as necessidades da criança. Educação, Porto Alegre, v. 62, n. 2, p. 313-336, maio/ago. 2007.

DALBOSCO, Claudio Almir. Paradoxos da educação natural no Émile de Rousseau: os cuidados do adulto. Educ. Soc., Campinas, vol. 30, n. 106, p. 175-193, jan./abr. 2009.

DALBOSCO, Claudio Almir. Educação natural em Rousseau. Das necessidades da criança e dos cuidados do adulto. São Paulo: Editora Cortez, 2011.

DALBOSCO, Claudio Almir. O lugar do Émile na arquitetônica do pensamento de Rousseau: problemas de vínculo entre educação e política. Veritas. Porto Alegre, v. 61, n. 1, jan.-abr. 2016, p. 7-25

DELGADO, Jorge Velázquez. Consideraciones en torno a la filosofía política de JeanJacques Rousseau. In. BENÍTEZ, Roberto Sánchez; MÁRQUEZ, Víctor Manuel 


\section{T usm Eutlaghat}

ISSN: 1984-6444 | http://dx.doi.org/10.5902/1984644431798

Hernández (Orgs.). La multiplicidad de Rousseau. Barcelona: Anthropos Editorial; Ciudad Juárez (México): Universidad Autónoma de Ciudad Juárez, 2016, p. 33-56.

GOETHE, Johan Wolfgang von. Anos de aprendizado de Wilhelm Meister. Trad. Nicolino Simone Neto. São Paulo: Ensaio, 1994.

GÓMEZ, Adolfo Lizárraga. Educación y libertad. El Emilio o de la educación de JeanJacques Rousseau. In. BENÍTEZ, Roberto Sánchez; MÁRQUEZ, Víctor Manuel Hernández (Orgs.). La multiplicidad de Rousseau. Barcelona: Anthropos Editorial; Ciudad Juárez (México): Universidad Autónoma de Ciudad Juárez, 2016, p. 189-207.

HERB, Karlfriedrich. Luz e sombra: o público e o privado em Jean-Jacques Rousseau e Hannah Arendt. Philósophos. Goiânia, v. 7, n. 1 p. 75-90, 2002.

HOTTOIS, Gilbert. Historia de la filosofia: del renacimiento a la posmodernidad. Madrid: Ediciones Cátedra, 1999.

PLATÃO. A República. Trad. Maria Helena da Rocha Pereira. 9. ed. Lisboa: Fundação Calouste Gulbenkian, 2001.

REALE, Giovanni; ANTISERI, Dario. História da filosofia: do humanismo a Kant. São Paulo: Paulus, 1990.

ROUSSEAU, Jean-Jacques. Discurso sobre a origem e os fundamentos da desigualdade entre os homens. São Paulo: Nova Cultural, 1991.

ROUSSEAU, Jean-Jacques. Emílio ou da educação. 3.ed. Rio de Janeiro: Bertrand Brasil, 1995.

ROUSSEAU, Jean-Jacques. O contrato social. 3. ed. São Paulo: Martins Fontes, 1996.

SOËTARD, Michel. Jean-Jacques Rousseau. Trad. Verone Lane Rodrigues Doliveira. Recife: Fundação Joaquim Nabuco/Editora Massangana, 2010.

STAROBINSKI, Jean. Jean-Jacques Rousseau: a transparência e o obstáculo. Tradução Maria Lúcia Machado. São Paulo: Companhia das Letras, 1991.

STRECK, Danilo R. Rousseau \& a educação. Belo Horizonte: Autêntica, 2008.

\section{Correspondência}

Fernando Dala Santa - Universidade de Passo Fundo - ROD BR 285, KM 292,7 São José, CEP 99052-900, Passo Fundo, Rio Grande do Sul, Brasil. 


\section{N uss

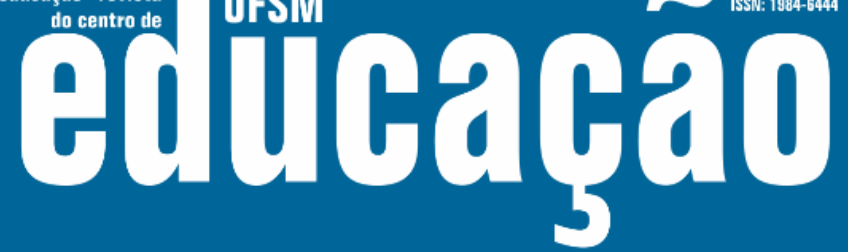

ISSN: 1984-6444 | http://dx.doi.org/10.5902/1984644431798

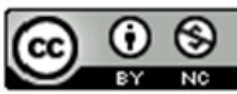

This work is licensed under a Creative Commons Attribution-NonCommercial 4.0 International (CC BY-NC 4.0)

\section{Notas}

\footnotetext{
${ }^{1}$ Doravante iremos nos referir à obra simplesmente como Emílio

${ }^{2} \mathrm{Na}$ França o lluminismo ficou conhecido como les Lumiéres, enquanto na Inglaterra recebeu o nome de Enlightenment e na Alemanha Aufklärung.

${ }^{3}$ Beantwortung der Frage: Was ist Aufklärung? Também traduzido como Resposta à pergunta: que é o iluminismo?

${ }^{4}$ Discurso sobre a origem e os fundamentos da desigualdade entre os homens.

${ }^{5}$ A admiração por Platão é declarada já no início do Livro I do Emílio, quando Rousseau afirma que a República "é o mais belo tratado de educação que jamais se escreveu" (ROUSSEAU, 1995, p. 14).
} 